\title{
INJURY, INFLAMMATION AND IMMUNITY
}

$\mathrm{T}$ HE first section of an international symposium on "Injury, Inflammation and Immunity" was held on May 5, at the Miles-Ames Research Laboratories, Stoke Poges, under the chairmanship of Sir Howard Florey.

This section covered the anatomical, physiological and pharmacological aspects of inflammation.

The symposium was opened by Prof. H. Ruska (Dusseldorf) with a paper on the structure of capillaries and response to chemical injuries, discussing the electron microscopical study of capillaries. He said that capillaries from different tissues varied greatly in respect of the presence or absence of a basement membrane, vesiculation or pores. The presence or absence of these structures appears to be correlated with the permeability of the vessels.

The effect of various chemical agents on capillary permeability was correlated with the changes in capillary wall as assessed by the electron microscope.

Dr. R. Robineaux (Paris) showed a film of the microscopical appearance under phase contrast of cells in spleen explants using the 'Cellophane'-strip tissue culture technique, between the eleventh and twenty-first day of culture. Up to the sixteenth day of culture lymphocytes and plasma cells were seen in close cellular relation to macrophages and reticular cells. Plasma cells were seen in mitosis. After 21 days the culture was transformed into macrophages which absorbed the other cells. Explants were from guinea pig spleen and plasma cells developed under the antigenic influence of chick embryo extract in the culture fluid.

Prof. G. Asboe-Hansen (Copenhagen) discussed the connective tissue response to injury, especially emphasizing mast cell degranulation and the accum. ulation of chondroitin sulphate and other mucopoly. saccharides in ground substance as a result of tissue injury. The increase in chondroitin sulphate was demonstrated by the uptake of sulphate labelled with sulphur-35 in the ground substance.

The effect of various hormones (for example, thyroidstimulating hormone and corticoids) on the repair mechanism were discussed with reference to their effect on mast cells and the accumulation of acid mucopolysaccharides in the ground-substance.

Dr. W. G. Spector (London), in a paper on endo. genous inflammatory mechanisms in the rat, described experiments on the pharmacological content of the turpentine-induced pleural effusion in the rat. $\mathrm{He}$ described two phases: an early phase associated with the presence of histamine and serotonin lasting $1 \mathrm{hr}$. was succeeeded by a delayed phase associated with pharmacological agents resembling $S R S-A$ and bradykinin. The early phase was retarded by antihistamine drugs without affecting the development of the later phase.

The role of peptides in the first stages of inflamma. tion was the subject of the next paper, by Dr. G. P. Lewis (London), which discussed some of the proteinbreakdown products responsible for the effects of inflammation. Among these he laid particular emphasis on bradykinin, a nonapeptide produced by the action of certain enzymes on plasma globulin. Bradykinin was capable of producing all four of the cardinal signs of the inflammatory response-vaso- dilation, increased capillary permeability, pain and the accumulation of leucocytes. He also discussed the enzymes capable of breaking down globulin to the active peptide and enzymes, kininases, which were in their turn capable of breaking down and controlling the concentration of these plasma kinins. Histamine was shown to play a part in activating plasma-kinin-forming activity and also enhanced the passage of these peptides into the tissues by increasing capillary permeability.

Prof. C. de Duve (Louvain) discussed lysosomes and cell injury. Lysosomes are small cytoplasmic sack-like structures surrounded by a lipoprotein membrane containing a number of enzymes. These enzymes, including cathepsin $\beta$-glucuronidase and acid phosphatase, are those which take part in all autolysis but are inactive so long as the lipoprotein membrane remains intact. They could be shown to be released under a number of pathological conditions, that is, in the liver after ligation of a lobe, or in the comatose animal, in the thymus after treatment with cortisone or in the spleen after X-irradiation. They also accumulated in states of physiological autolysis, for example, the regression of Mullerian ducts in the male chick embryo and in the regression of the tadpole tail. He postulated four possible mechanisms of the action of lysosomal enzymes in tissues: (1) the intracellular release of enzyme attacking the cell; (2) diffusion of these enzymes out of the cell, attacking other cells; (3) selective retention of phagocytes rich in lysosomes; (4) colonization of the tissue with phagocytes rich in lysosomes.

The final two papers were on the inflammatory and biochemical aspects of burns. The first was on inflammatory changes in burned skin by Dr. S. Sevitt (Birmingham), who discussed three types of increased capillary permeability, an immediate transient type which was due to release of histamine and was abolished by antihistamine drugs, an early form which was more severe leading to stasis and a delayed form occurring around and deep to the early response. He found that the critical temperature at which capillaries leaked protein was $41^{\circ}-44^{\circ} \mathrm{C}$. and this correlated with the critical temperature for formation of bradykinin. The critical temperature for capillary stasis was $47^{\circ}-48^{\circ} \mathrm{C}$.

'The last paper was by Dr. J. Kohn (London) on biochemical and immunological aspects of human burns, discussing the electrophoresis of enzymes in blister fluid, the increased concentration of histamine and a bradykinin-like substance in the urine of patients with burns. Following the reports of the beneficial effect of convalescent serum in cases of severe burns attempts were made to demonstrate precipitating antibodies in the serum of patients with burns against antigens derived from the burned tissues, but these had met with very little success. However, he had found an unusually high level of precipitating antibody against staphylococcal antigens in the serum of patients with severe burns.

The second section of the symposium was at the Instituto Miles de Terapeutica Experimental in Mexico City during May 10-11, and the final section at the Miles Laboratories, Inc., Elkhart, Indiana, during May 15-16. J. L. ToRK 